\title{
Consequences of chronic diseases and other limitations associated with old age - a scoping review
}

Petra Maresova ${ }^{1}$, Ehsan Javanmardi', Sabina Barakovic ${ }^{2}$, Jasmina Barakovic Husic ${ }^{3}$, Signe Tomsone ${ }^{4}$, Ondrej Krejcar ${ }^{5}$ and Kamil Kuca ${ }^{5,6^{*}}$ (D)

\begin{abstract}
Background: The phenomenon of the increasing number of ageing people in the world is arguably the most significant economic, health and social challenge that we face today. Additionally, one of the major epidemiologic trends of current times is the increase in chronic and degenerative diseases. This paper tries to deliver a more up to date overview of chronic diseases and other limitations associated with old age and provide a more detailed outlook on the research that has gone into this field.

Methods: First, challenges for seniors, including chronic diseases and other limitations associated with old age, are specified. Second, a review of seniors' needs and concerns is performed. Finally, solutions that can improve seniors' quality of life are discussed. Publications obtained from the following databases are used in this scoping review: Web of Science, PubMed, and Science Direct. Four independent reviewers screened the identified records and selected relevant publications published from 2010 to 2017. A total of 1916 publications were selected. In all, 52 papers were selected based on abstract content. For further processing, 21 full papers were screened."

Results: The results indicate disabilities as a major problem associated with seniors' activities of daily living dependence. We founded seven categories of different conditions - psychological problems, difficulties in mobility, poor cognitive function, falls and incidents, wounds and injuries, undernutrition, and communication problems. In order to minimize ageing consequences, some areas require more attention, such as education and training; technological tools; government support and welfare systems; early diagnosis of undernutrition, cognitive impairment, and other diseases; communication solutions; mobility solutions; and social contributions.

Conclusions: This scoping review supports the view on chronic diseases in old age as a complex issue. To prevent the consequences of chronic diseases and other limitations associated with old age related problems demands multicomponent interventions. Early recognition of problems leading to disability and activities of daily living (ADL) dependence should be one of essential components of such interventions.
\end{abstract}

Keywords: Chronic diseases, Seniors' needs, Elderly disability, activities of daily living

\footnotetext{
*Correspondence: kamil.kuca@uhk.cz

${ }^{5}$ Center of Basic and Applied Research, Faculty of Informatics and Management, University of Hradec Kralove, Rokitanskeho 62, 50003 Hradec Kralove, Czech Republic

${ }^{6}$ Malaysia Japan International Institute of Technology (MJIIT), Universiti Teknologi Malaysia Kuala Lumpur, Jalan Sultan Yahya Petra, 54100 Kuala Lumpur, Malaysia

Full list of author information is available at the end of the article
}

(c) The Author(s). 2019 Open Access This article is distributed under the terms of the Creative Commons Attribution 4.0 International License (http://creativecommons.org/licenses/by/4.0/), which permits unrestricted use, distribution, and reproduction in any medium, provided you give appropriate credit to the original author(s) and the source, provide a link to the Creative Commons license, and indicate if changes were made. The Creative Commons Public Domain Dedication waiver (http://creativecommons.org/publicdomain/zero/1.0/) applies to the data made available in this article, unless otherwise stated. 


\section{Introduction}

The phenomenon of the increasing ageing population is one of the most important economic, social, and medical issues of current times. Recent demographic trends outline that the number of people of old age will continue to rise dramatically. Today most people can expect to live to age 60 and beyond [1]. Between 2000 and 2020, the fastest growing segment of the United States (US) population will be individuals aged 65 years and older [2]. By 2030, the number of people in the world aged 60 years or over will increase by $56 \%$, and by 2050 , the global population of senior persons is projected to more than double its size in 2015. The number of people aged 65 or older is about to grow to nearly 1.5 billion in 2050 , with most of the increase in developing countries [3]. These demographic transitions essentially require shifting the global focus to cater for the preventive healthcare and medical needs of the elderly population [4]. A wide gamut of determinants, such as social concerns and maltreatment of elderly individuals, poor knowledge and awareness about the risk factors, food and nutritional requirements, psycho-emotional concerns, financial constraints, health care system factors, and physical correlates determine the medical problems and thus cast a significant impact on the quality of life (QoL) of elderly individuals [5-8].

The ageing population tends to have a higher prevalence of chronic diseases worldwide today [9]. For example, six in ten adults in the US have a chronic disease and four in ten adults have two or more [10], while Sweden reports multiple chronic conditions of $56.3 \%$ [11]. These chronic conditions are significant and profound economic issue for any person, the healthcare system, and society as a whole [12]. Such diseases account for $86 \%$ of all medical costs in the US being even greater worldwide [13]. The presence of multiple chronic conditions in the same individual has profound implications for healthcare costs and utilisation [14]. For example, a Swiss study estimated that the average total healthcare costs were 5.5 times higher in elderly patients with multiple chronic conditions as compared with elderly patients without multiple chronic conditions [15]. The combined cost savings from the health and productivity that results from a small reduction in the prevalence of chronic disease cannot be ignored, resulting in a genuine return on investment in a very small span of time [16].

Chronic diseases require a long period of treatment that leads to the increase in demand for healthcare services and changes its nature [17-21]. This need for long-term care can lead to a decline in the QoL of elderly individuals [22]. This phenomenon will put pressure on healthcare systems to adapt in order to meet these changing demands. New and emerging technologies have the potential to change healthcare at home and in community [23]. Recognising the needs of elderly individuals suffering from chronic diseases and other constraints would fix many problems that patients face and results in an improved QoL, safety and overall health. Also, by investing in better QoL, safety and overall health in elderly, their productivity will rise as well thereby contributing to the economic and social opportunities.

This paper will be presenting an up-to-date survey of the limitations of seniors in connection with their chronic diseases and helps to provide a more detailed image of the research that has been done in this field. Additionally, the paper underlines the main research areas within seniors' needs in relation to chronic diseases and the limitations associated as an informative summary for further research. To appreciate the scientific progress that has been made, with an emphasis on the literature dedicated to the economic field, a systematic review has been conducted by using keywords such as elderly activities of daily living (ADLs), elderly QoL, and elderly instrumental activities of daily living (IADLs).

This paper is organized as follows: After the Introduction covering the background for this research given in the first section, section 2 describes in detail the used methodology. The challenges faced by seniors with chronic diseases and other limitations associated with old age are specified in section 3. After reviewing seniors' needs and concerns, the solutions that can improve their QoL are discussed in section 4. Finally, section 5 concludes the paper and gives open research areas for the future activities.

\section{Methods}

This scoping review is performed to identify and summarise up-to-date conditions leading to ADLs dependency in relation to chronic diseases and other limitations associated with old age. "A 4-step systematic review was conducted using empirical studies: locating and identifying relevant articles; screening located articles; examining full-text articles for inclusion or exclusion; and a detailed examination of the 21 articles included."

\section{Search strategy and eligibility criteria}

In February 2018, four investigators performed a systematic literature search of the Web of Science, PubMed, and Science Direct. The period of interest covered the years from 2010 to 2017, and the electronic search included the following keywords: elderly and (Activities of daily living) ADLs, elderly QoL, elderly and (Instrumental Activities of daily living) IADLs, senior and ADLs, and senior and ADLs.

"In the Web of Science database, 829 publications were identified. Only two types of publications were 
considered eligible for the purpose of this study: 'article' and 'review', which includes the following: 'review articles', 'research articles', 'data articles', 'book reviews', 'mini reviews', 'product reviews', and 'video articles'. This criterion reduced the initial set of papers to a total of 172 research articles, which were selected for further processing. For PubMed and Science Direct, a semiautomated framework or aiding surveys was used [24]. The framework first used the search tools of the libraries with the aforementioned keywords. Next, after eliminating duplicate records from the retrieved papers, it analysed the title, abstract, and keywords section of each paper to evaluate whether any of the following properties or their synonyms (listed in parenthesis) were mentioned: ADLs and IADLs. The paper distribution based on property (keyword) is presented in Table 1."

ADLs (or ADL) is a term used in healthcare to refer to people's daily self-care activities. Common ADLs include feeding, bathing, dressing, grooming, working, homemaking, cleaning after defecating, and leisure [25]. Adaptive equipment and devices may be used to enhance and increase independence in performing ADLs. Basic ADLs consist of self-care tasks that include but are not limited to, bathing and showering, personal hygiene and grooming, dressing, toilet hygiene, functional mobility, and self-feeding. One way to think about basic ADLs is that they are the things many people do when they get up in the morning and get ready to go out of the house: get out of bed, go to the toilet, bathe, dress, groom, and eat [26]. IADLs, such as cleaning and maintaining the house, preparing meals, shopping, managing money, moving within the community and many other activities are not necessary for fundamental functioning, but they let an individual live independently in a community [27]."

This paper includes 1916 publications that were acquired based on a given set of properties from different databases. The publications were automatically analysed and assessed, and then four properties were chosen to be further processed from the existing pool. False positive papers that had the relevant properties but were not relevant to the study at hand were discarded manually after being checked. This resulted in the overall pool of studies being narrowed down to 52 papers and articles. This set was then processed further, and the final number was brought down to 21 full length papers subsequent to the manual and semi-auto search. This excluded papers that did not fall into the description underscored in subsection 2.2.

\section{Data extraction and study quality evaluation}

Each publication's data was extracted - the main team consisted of four researchers that worked to outline data individually. The following data was extracted: the country and type of study, the study's author, and the study's title. A study was included if it qualified as per the following requirements:

- Published after 2010;

- Focused on chronic diseases and other limitations associated with old age;

- Posed questions concerning seniors' needs;

- Described diseases or specific needs of seniors;

- Discussed the limitations of seniors in connection with their chronic diseases;

- Focused on elderly individuals' QoL and ADLs;

- Focused on older people's community-dwelling; and

- It was in English.

A publication was not included if any of the following were true:

- It was not in English;

- It included a theoretical model;

- Focused on a technical description of the solution;

- Described systems for the diagnosis of the disease;

- Described healthcare management systems; and

- Focused on a disease rather than focusing on the patient.

Search process is described in Fig. 1.

Table 1 Paper distribution by property

\begin{tabular}{llll}
\hline Key words (used 'AND' between all words) & WOS & Science Direct & PubMed \\
\hline ADLs (activities of daily living) & 107 & 23 & 109 \\
Elderly ADLs & 1 & 3 & 129 \\
Elderly quality of life & 697 & 4 & 780 \\
IADLs (instrumental activities of daily living) & 22 & 0 & 24 \\
Elderly IADLs & 0 & 1 & 0 \\
Senior ADLs & 1 & 0 & 0 \\
Senior IADLs & 1 & 160 & 927 \\
Total & 829 & & 0 \\
\hline
\end{tabular}




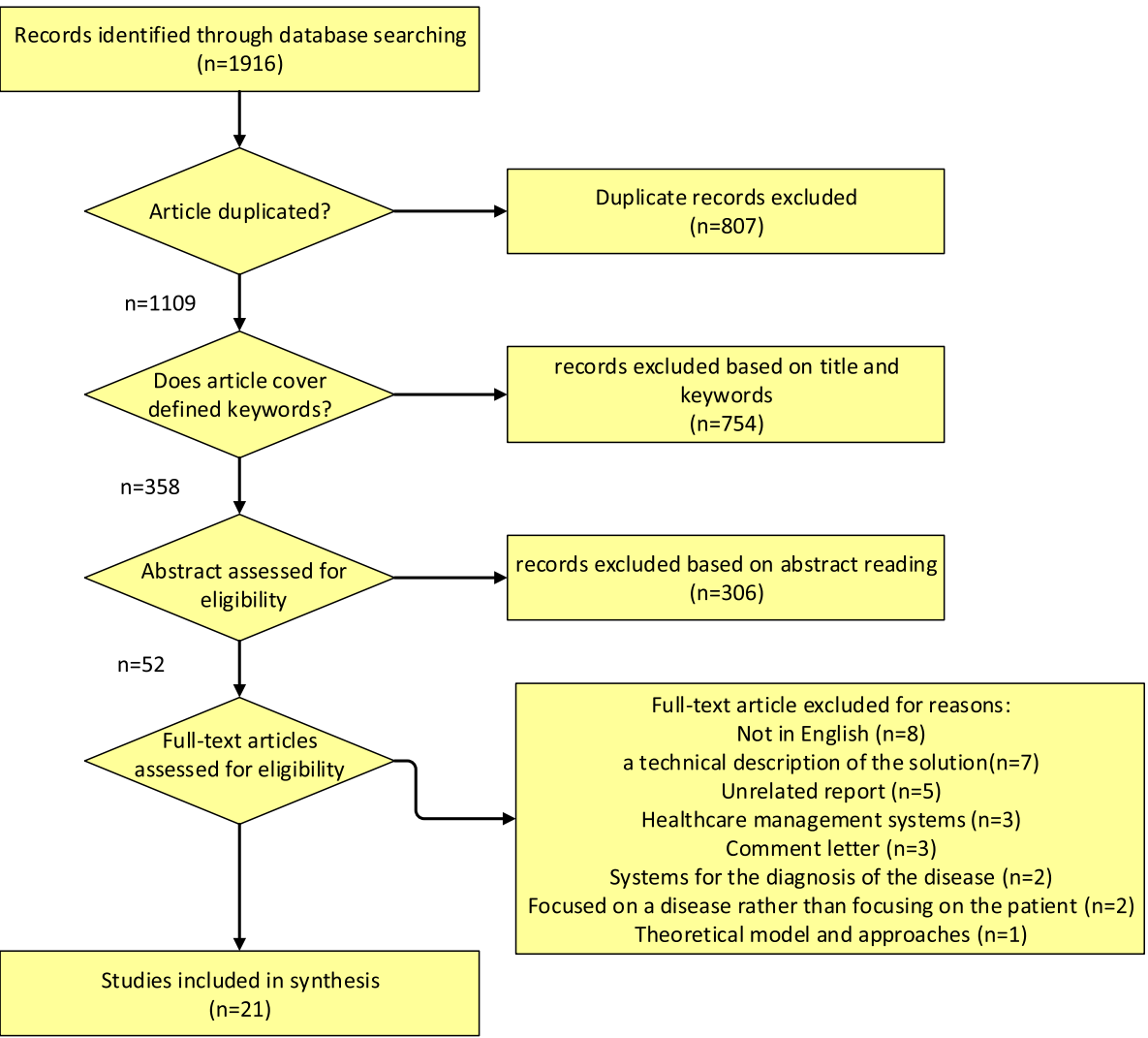

Fig. 1 Publication search process according to PRISMA

\section{Results}

Current research on ageing problems and seniors' ADLs dependency is described in Table 2. For each study, the objectives, problems and diseases, main findings, and limitations are described. Elderly persons will, as they age, continue to progressively decline in terms of their functional capacity. This will affect their frailty, worsen dependency and add to their loss of autonomy [48]. Ageing results in considerable and consistent change in an organism and results in a decline of or limited physical function and an augmented level of comorbidity [40].

Identified major problems that cause seniors' ADL dependency are classified as follows:

- Disabilities and unmet needs are mentioned in 13 articles.

- Psychological problems are mentioned in six articles.

- Difficulties in mobility are mentioned in four articles.

- Poor insight and cognitive function are mentioned in four articles.

- Falls and incidents are mentioned in four articles.

- Wounds and injuries are mentioned in three articles.

- Prevalence of undernutrition and dysphagia are mentioned in three articles.
- Communication problems are mentioned in one article.

The prevalence and the number of comorbidities increase with age, which might lead to ADL dependency [40]. Part of the potential causal pathway by which the aforementioned problems directly or indirectly affect ADL in elderly people is presented in Fig. 2(a) and (b) [34]. In Fig. 2(a), the findings of the selected studies revealed that as a person ages, his/her psychological issues are intensified and $\mathrm{s} /$ he feels more unmet needs [31-33, 36, 44]. Furthermore, aging is a factor that could increase the range of disabilities, reduce cognitive abilities, and increase problems related to the teeth, swallowing and nutrition [30, 34] -[42]. Along with these issues, as research has shown, older people find it more difficult to perform everyday activities, move around, and communicate with others; meanwhile they are more likely to fall down, experience incidents, and suffer from wounds and different types of injuries [29, 39, 41]. In Fig. 2(b), there is a conceptual model showing the mutual effects of some aging-related problems on activities of daily living (ADLs). As this dynamic cause-effect diagram illustrates, reduced cognitive abilities and oral hygiene mutually affect each other. Problems could lead to malnutrition in 


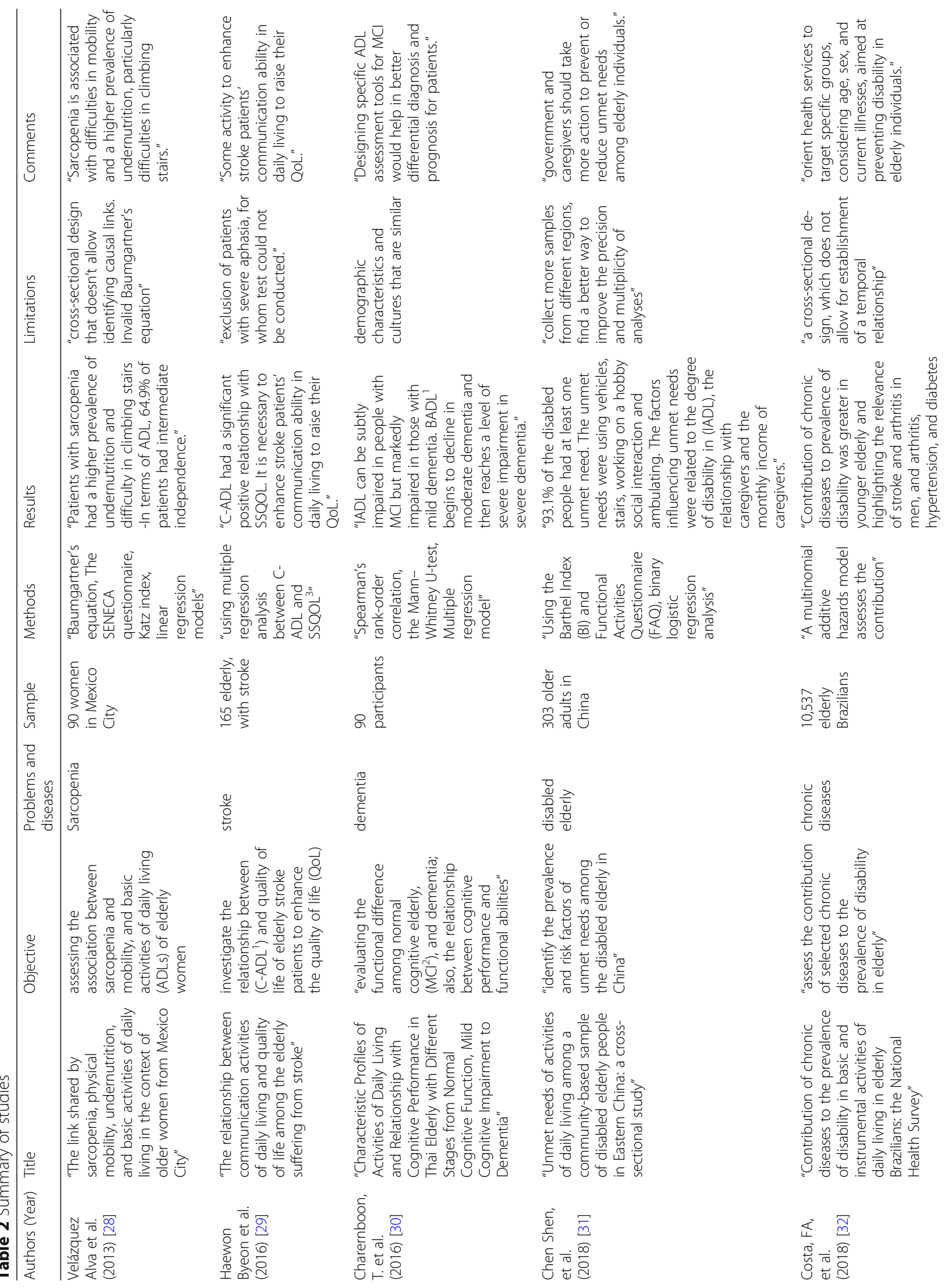




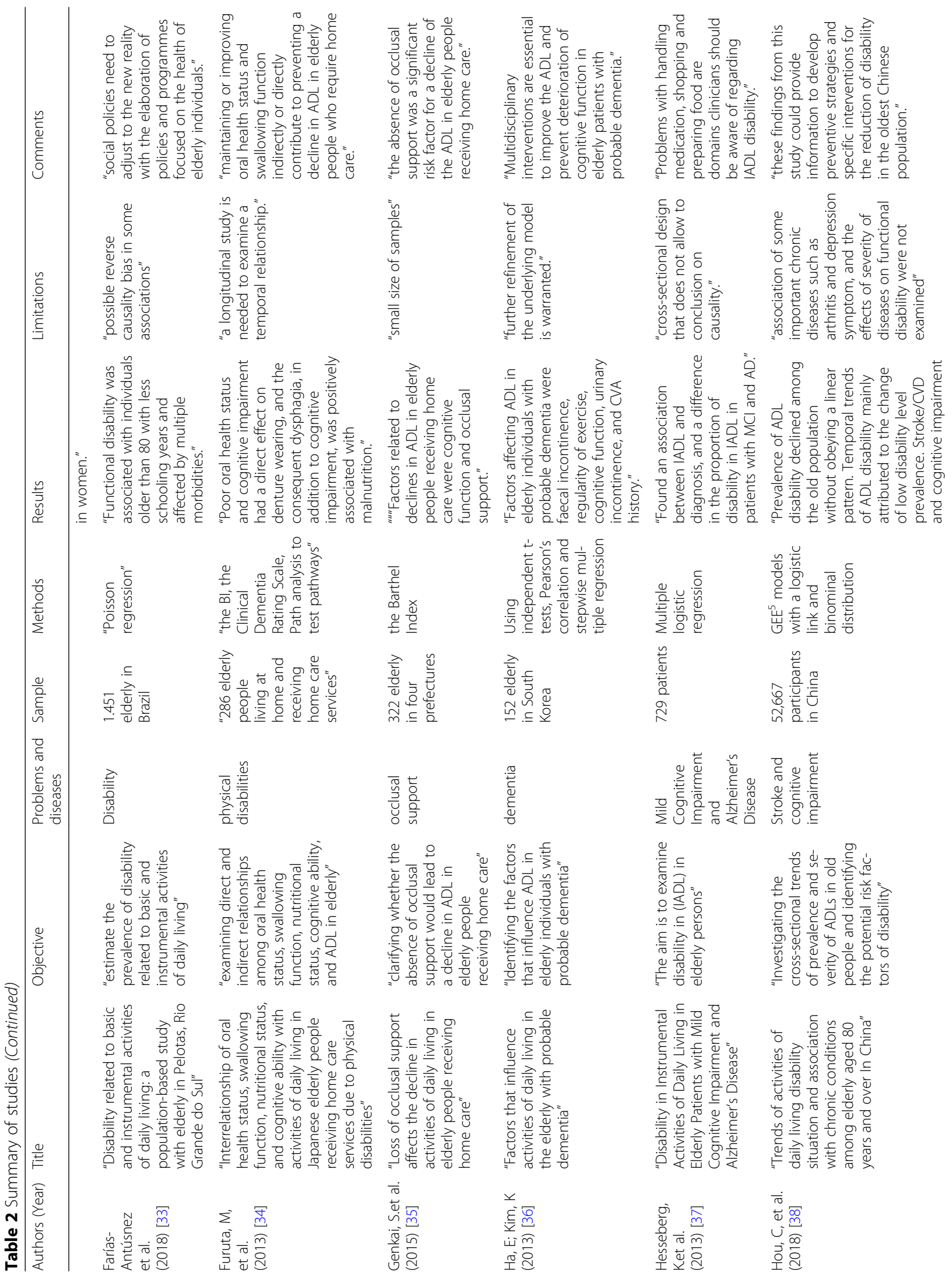




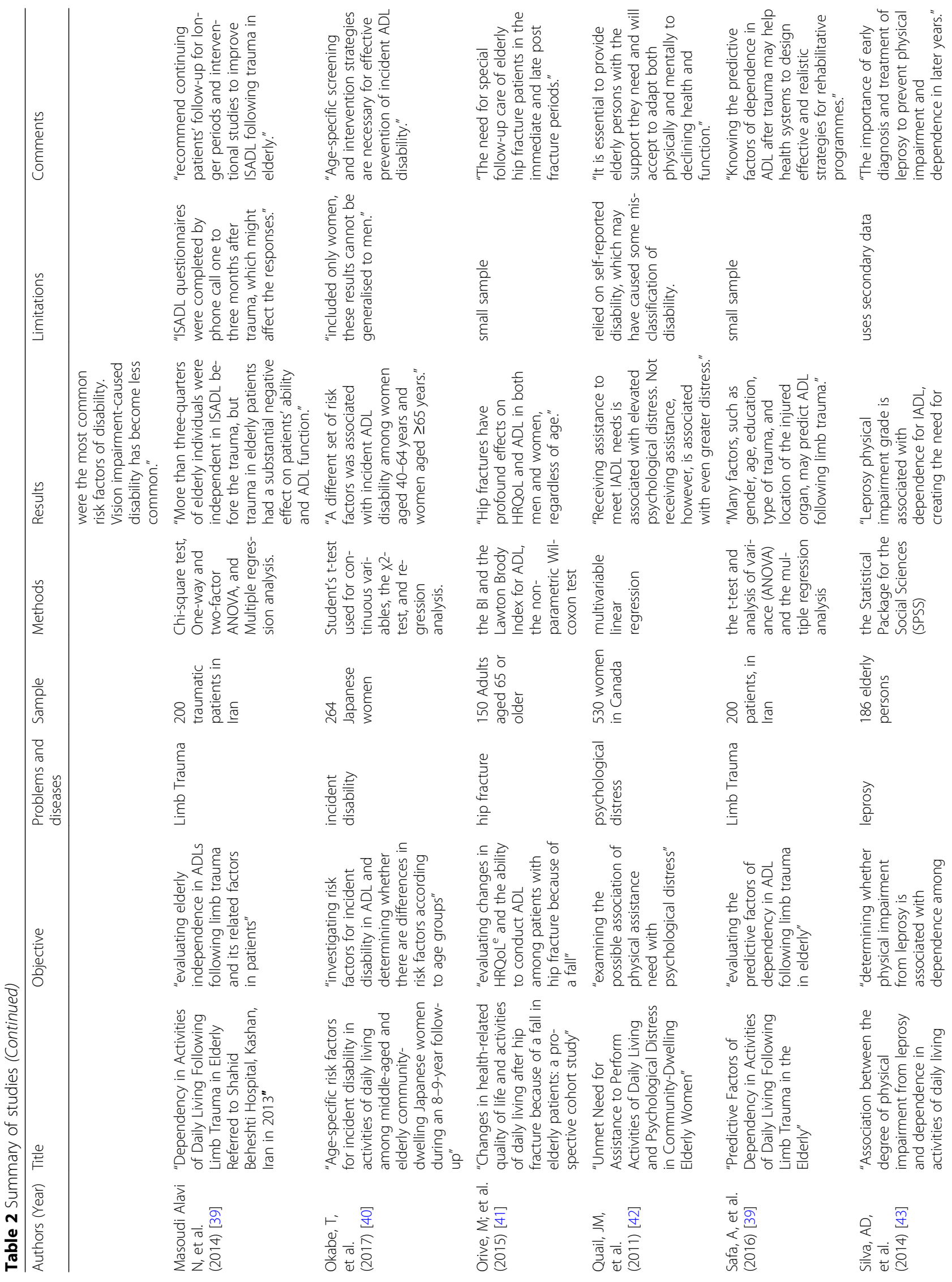




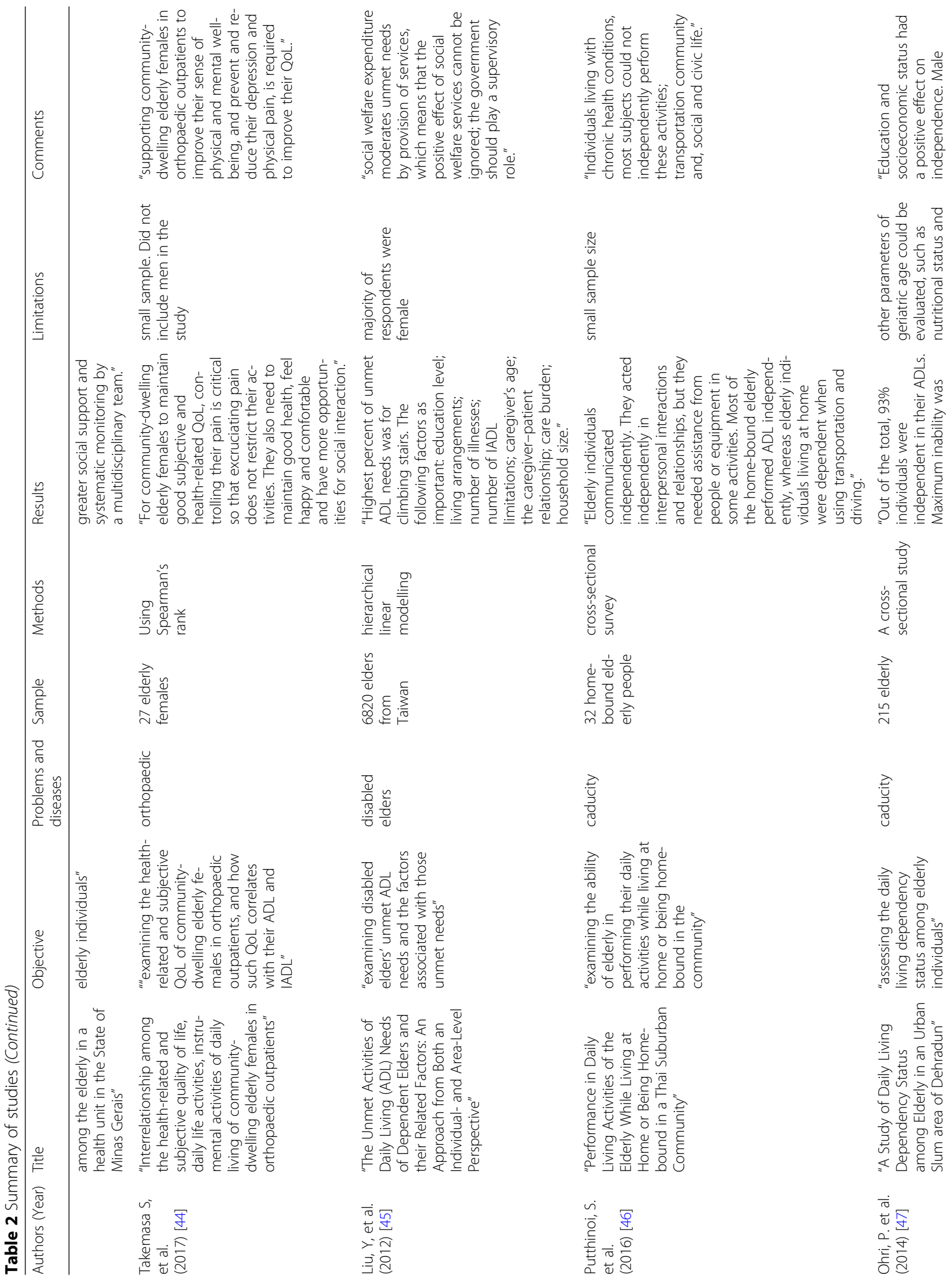




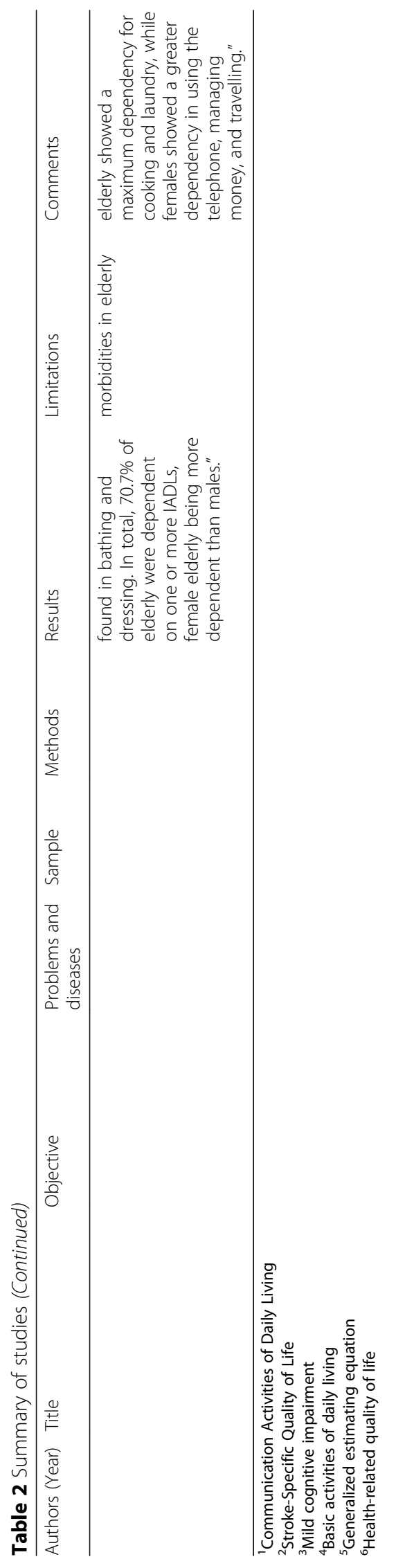




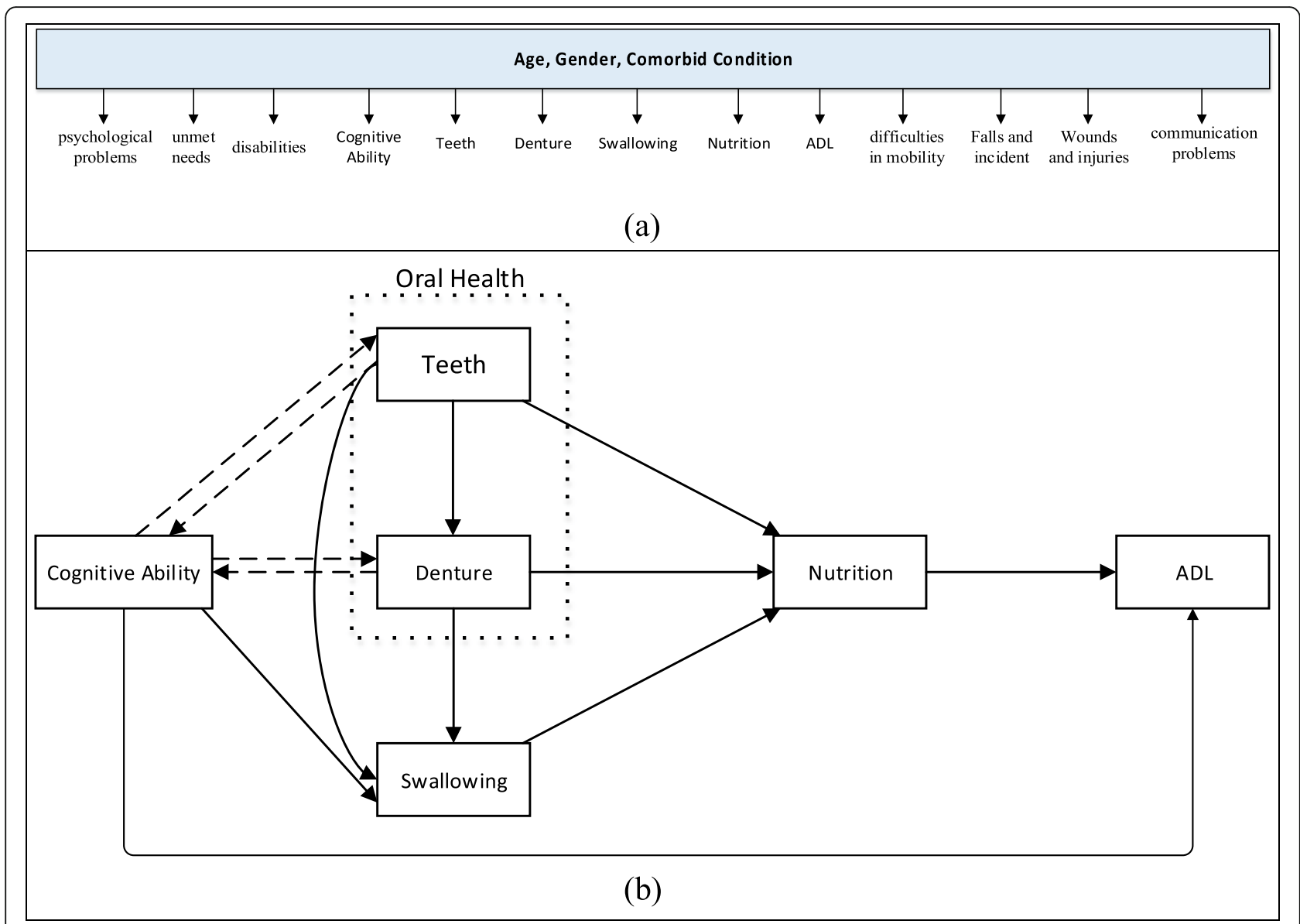

Fig. 2 (a) Age, gender, and comorbid condition are factors that affect seniors' conditions. (b) Part of the potential causal pathway by which problems directly or indirectly affect ADL in elderly people. ADL in elderly individuals is impaired by several factors [34]

the elderly. The swallowing function, cognitive abilities, and the quality of nutrition can directly affect ADLs.

Table 3 shows the various problems and their impacts on the seniors' ADL on the basis of selected articles.

\section{Disabilities and unmet needs}

Disability is one of the most common problems in seniors that leads to ADL dependence; dependence in ADL and IADL is a critical "challenge for communitydwelling elderly people, regardless of whether their needs are met or unmet. As the elderly population continues to grow, the challenges involved in addressing disability and unmet need will also grow [42]. Frailty describes the condition of elderly persons with the highest risk of disability, institutionalisation, hospitalisation, and death [49]. Chronic conditions have been confirmed as the main causes of disability [38]."

"Diseases show a greater contribution to the prevalence of more severe disability, that is, with impairment of basic ADL. Elderly patients with a diagnosis of arthritis, stroke, or diabetes should be monitored more effectively by considering the important contribution of these conditions to disability. Stroke and arthritis were the diseases that contributed most consistently to disability, independent of sex and age bracket. Hypertension and heart disease showed only a significant contribution to the prevalence of both levels of disability in women [32, 33]. Disabling effects of multimorbidity increased in ADL dependency [38]."

"Disabilities after stroke become chronic, and the inability to independently perform ADLs, such as dressing and eating, in a long run causes helplessness and depression in stroke patients and inflicts emotional pain, such as intellectual regression, despair, and anxiety. Functional disorders in daily life in long term are likely to cause deterioration in QoL of stroke patients and maladjustment in social relationships, changes in role, and economic difficulties [30].

"Having knee joint or back pain was significantly associated with a higher risk of incidence of ADL dependency. Older adults with pain have a higher risk of developing incident ADL dependency and commonly have functional limitations. Speculation has indicated that in mutual feedback loops in which pain and 
Table 3 Problems of elderly people and the articles that refer to them

\begin{tabular}{|c|c|c|c|c|c|c|c|c|}
\hline Authors (Year) & $\begin{array}{l}\text { Disabilities and } \\
\text { unmet needs }\end{array}$ & $\begin{array}{l}\text { Psychological } \\
\text { problems }\end{array}$ & $\begin{array}{l}\text { Difficulties } \\
\text { in mobility }\end{array}$ & $\begin{array}{l}\text { Poor insight and } \\
\text { cognitive function }\end{array}$ & $\begin{array}{l}\text { Falls and } \\
\text { incident }\end{array}$ & $\begin{array}{l}\text { Prevalence of } \\
\text { undernutrition and } \\
\text { dysphagia }\end{array}$ & $\begin{array}{l}\text { Wounds } \\
\text { and } \\
\text { injuries }\end{array}$ & $\begin{array}{l}\text { Communication } \\
\text { problems }\end{array}$ \\
\hline $\begin{array}{l}\text { Velázquez Alva } \\
\text { et al. (2013) [28] }\end{array}$ & & & * & & & * & & \\
\hline $\begin{array}{l}\text { Haewon Byeon } \\
\text { et al. } \\
\text { (2016) [29] }\end{array}$ & * & * & & & & & & * \\
\hline $\begin{array}{l}\text { Charernboon, T. } \\
\text { et al. } \\
\text { (2016) [30] }\end{array}$ & & & & * & & & & \\
\hline $\begin{array}{l}\text { Chen Shen, } \\
\text { et al. } \\
\text { (2018) [31] }\end{array}$ & * & * & & & & & & \\
\hline $\begin{array}{l}\text { Costa, FA, et al. } \\
\text { (2018) [32] }\end{array}$ & * & * & & & & & & \\
\hline $\begin{array}{l}\text { Farías-Antúş̧nez } \\
\text { et al. } \\
\text { (2018) [33] }\end{array}$ & * & & & & & & & \\
\hline $\begin{array}{l}\text { Furuta, M, et al. } \\
\text { (2013) [34] }\end{array}$ & * & & & * & & * & & \\
\hline $\begin{array}{l}\text { Genkai, S.et al. } \\
\text { (2015) [35] }\end{array}$ & & & * & & & * & & \\
\hline $\begin{array}{l}\mathrm{Ha}, \mathrm{E} ; \mathrm{Kim}, \mathrm{K} \\
(2013)[36]\end{array}$ & & * & & * & & & & \\
\hline $\begin{array}{l}\text { Hesseberg, } \\
\text { K.et al. } \\
(2013) \text { [37] }\end{array}$ & & & & * & & & & \\
\hline $\begin{array}{l}\text { Hou, C, et al. } \\
\text { (2018) [38] }\end{array}$ & * & & & & & & & \\
\hline $\begin{array}{l}\text { Masoudi Alavi } \\
\text { N, et al. } \\
\text { (2014) [39] }\end{array}$ & * & & * & & $*$ & & $*$ & \\
\hline $\begin{array}{l}\text { Okabe, T, et al. } \\
\text { (2017) [40] }\end{array}$ & * & & * & & * & & & \\
\hline $\begin{array}{l}\text { Orive, } \mathrm{M} \text {; et al. } \\
\text { (2015) [41] }\end{array}$ & & & & & * & & & \\
\hline $\begin{array}{l}\text { Quail, JM, et al. } \\
\text { (2011) [42] }\end{array}$ & * & * & & & & & & \\
\hline $\begin{array}{l}\text { Safa, A, et al. } \\
\text { (2016) [39] }\end{array}$ & * & & & & * & & * & \\
\hline $\begin{array}{l}\text { Silva, AD, et al. } \\
\text { (2014) [43] }\end{array}$ & & & & & & & * & \\
\hline $\begin{array}{l}\text { Takemasa S, } \\
\text { et al. } \\
\text { (2017) [44] }\end{array}$ & & * & & & & & & \\
\hline $\begin{array}{l}\text { Liu, Y, et al. } \\
\text { (2012) [45] }\end{array}$ & * & & & & & & & \\
\hline $\begin{array}{l}\text { Putthinoi, S. } \\
\text { et al. } \\
\text { (2016) [46] }\end{array}$ & * & & & & & & & \\
\hline $\begin{array}{l}\text { Ohri, P. et al. } \\
\text { (2014) [47] }\end{array}$ & * & & & & & & & \\
\hline
\end{tabular}


functional limitations are mutually reinforcing, pain exacerbates functional limitations and functional limitations exacerbate pain. Age-specific screening and intervention strategies might be necessary for effective prevention of incident ADL dependency among elderly women [40].

Individuals living with chronic health conditions, could not independently perform transportation, to engage in community, social, and civic life; majority had physical disabilities as a limited ability to conduct ADLs independently."Most persons were independent regarding basic ADLs, for example, self-care activities such as drinking, eating, dressing, and toileting. The activities reported as most dependent were driving, looking after one's health, and acquisition of goods and services, and assistance was required to perform more complex ADL tasks [46]. The highest percent of unmet ADL needs was for climbing stairs, and the lowest pertained to eating [45].

Dependency in ADL was found more in lower socioeconomic classes compared with higher socioeconomic classes. Compared with males, females are significantly more dependent regarding IADLs. Dependence significantly increased after 80 years of age. The dependence, however, was greater regarding IADL. Education and socioeconomic status have a positive impact on dependency status [47], mainly because learning opportunities can help people develop the skills and confidence to adapt and attempt a healthier ageing process. Elderly people who were working had a lower prevalence of disability for IADLs, which involve more complex activities, and functional disability in general because labour activity implies daily challenges that keep the worker active and contribute to the maintenance of their functional capacity. However, a critical assertion is that elderly individuals might not be working on the grounds of their disability [33].

These elements found to be the most significant: the level of education, the arrangements for living, the number of IADL limiters, the number of diseases, the age of the caregiver, the association of the patient with their caregiver, the size of the household, the burden of care, the link between the service uptake and the welfare expense, and the link between number of IADL limiters and welfare expense [45].

A person who has a mild dependency for care can change into a completely or severely dependent person if the intervention does not take place at the right time. Therefore, it is of utmost importance that care be provided early and that elderly people are monitored to ensure that their progression to complete dependency is slowed down as much as possible [31]. Approximately $93.1 \%$ of all disabled people of older age had at least one need that is unmet [31]. The results indicate that early intervention can help decrease the prevalence of reported diseases at more advanced ages [32].

\section{Psychological problems}

Unmet needs and disability can impact both mental and physical health. They can also reduce existing level of QoL and physical health in the context of elderly people. Disability can cause or worsen anxiety and depression, the two main elements that make up psychological distress. Both unmet and met IADL needs are linked to augmented mental distress. To put it simply, being IADL dependent is linked with heightened distress [42]. Caregivers will often only focus on the physical needs of a patient that falls in an older age range. However, activities such as social interaction or a hobby are often ignored, which is a problem. It has been observed that disabled elderly people will normally feel inferior and lose their confidence in regard to talking to other people [31]. Costa, FA, et al. in 2013 [32] showed that depression becomes more prevalent with age. The likelihood of a woman with a disability also showing signs of depression is very high, and the opposite link is also true with an increase in age [32]. Ha and Kim pointed out that as cognitive levels fall, even people that have no past history of mental issues are at risk for behaviour that stems from depression, including destructiveness, violence, agitation [36].

At times, disabled people will not have a choice but to remain in their homes or room. Some even stay in bed for a long period of time to avoid issues. However, not being outdoors for longer periods of time has a detrimental impact on a person's mental health and can lead to psychological distress for the elderly [31]. Especially regarding disability that impedes the basic activity of urinating or evacuating, this finding is worrying and can lead elderly individuals to experience social isolation, in addition to leading to changes in their self-esteem and self-image, reducing their QoL [33].

Quail, Wolfson, and Lippman in 2011 [44] believed that "there are differences in the severity of psychological distress based upon the type of activity in which a woman is disabled (Personal Activities of Daily Living (PADL) versus IADL) and whether the need for physical assistance is met or unmet. The unmet need to perform an IADL is associated with increased psychological distress over and above the level of distress related to meeting the IADL need. For example, for many women of older generations, cooking is a source of enjoyment. Dependency in meal preparation, regardless of whether the need is met or unmet, may lead to distress because of concerns about not wanting to be a burden, not being able to retain power to decide about meals, or not being able to maintain routine in daily living [42]. Elderly people need to maintain good health, feel happy and 
comfortable and have more opportunities for social interaction. To improve the QoL of community-dwelling elderly individuals in their communities, supporting them to improve their sense of physical and mental well-being and prevent and reduce their depression and physical pain is required [44]."

\section{Difficulties in mobility}

Malnutrition and cognitive impairment are associated with reduced physical performance and poor muscle strength, leading to disability and reducing the ability to perform basic ADLs [34]. Walking ability has a critical role in the ADL independence of older people [40]. Alva et al. in 2013 [28] described that women who are older and afflicted with sarcopenia find it more difficult to be physically mobile. This is particularly true when the try to climb stairs. The loss of skeletal muscle mass is linked to their decreased physical ability. Elderly women with sarcopenia, compared with those without sarcopenia, are approximately twice as likely to develop difficulties in using stairs [28].

Masoudi Alavi, Safa, and Kalahroudi showed in 2014 [39] that people with fractured hips have poor recovery, and this may impact their mobility, making the issue more permanent [39].

Another aspect was highlighted by Genkai et al. in 2013 [35], who said that occlusal support absence resulted in decreased mobility and physical activity. Muscle strength and a person's balance are extremely linked with their mobility. Strength in the lower extremities is normally higher in older people in good health as opposed to those who are not. People who have maintained good occlusal support are normally going to have better mobility. In effect, the findings show that occlusal support is essential if one is to preserve the ability to walk. Maintaining this ability has been linked with ADL. The research reviewed shows that occlusal support maintenance is an effective strategy to ensure that one's walking ability is also maintained [35].

\section{Poor insight and cognitive function}

"Elderly individuals with cognitive impairment may demonstrate minimal impairment in some complex IADLs. For example, tasks often found to be impaired in MCI usually include finances, telephoning, keeping appointments, driving and transportation, shopping, food preparation, and responsibility for medication [30, 37]."

"Cognitive function is a critical factor that affects ADL. Early detection of cognitive disorders is a critical strategy for lowering morbidity. The factors affecting ADL in elderly individuals are faecal incontinence, regularity of exercise, cognitive function, urinary incontinence, and CVA history [36]. Cognitive impairment causes potential problems related to the inability to eat or lack of access to food, hence leading to malnutrition [34]."

Differences in cultural and social background can have an effect on functional assessment. For instance, family structure in many nations consists of not just the immediate family but also the extended family. Therefore, patients with impairments of a cognitive nature typically live with their partners and children, in addition to their siblings and their partners and children. In this situation, it could prove difficult for the caregiver to actually determine how hindered a patient is in regard to performing a given activity. Furthermore, a good number of people might not even know enough about the symptoms of dementia, or its side effects. They think that many symptoms are simply normal for older people, including forgetfulness and ADL decline [30].

\section{Falls and incidents}

Taking a fall could be a marker for "normal" changes that an older person goes through. With age, a person's strength, gait and vision change. The most significant problem that one faces is the fractures that may result from a fall. Geriatric trauma injuries are also normally the result of a fall [39]."Decreased rapid walking speed increases the risk for falls and therefore increases ADL disability, either from the fracture or post-fall syndrome, in community-dwelling older adults [40]."

Any kind of fracture can have a terrible effect on ADLs; however, hip fractures are the worst. This shows that special follow up in the case of such patients is extremely needed, and this is true for both the postfracture period and the immediate time after it has occurred [41]. Elders can be trained to not get up too quickly in the morning and spend the first couple of minutes sitting on the edge so that they do not cause a fall or topple over [49].

\section{Wounds and injuries}

Trauma, wounds and injuries in older people have a considerable negative impact on their ability and ADL function [39]. The leprosy physical impairment grade is linked with IADL dependence, establishing the requirement for more social support and proper monitoring conducted by a multidisciplinary team. "There is a hierarchy in the process of frailty. First, independence is lost in advanced ADLs, and this loss is followed by a loss of independence in IADLs and, finally, BADLs. The followup and rehabilitation of these patients are essential [43].

\section{Prevalence of undernutrition and dysphagia}

"Undernutrition in elderly individuals is a common and important clinical entity that should be diagnosed early; for example, elderly individuals with sarcopenia had a higher prevalence of undernutrition [28]. Additionally, 
swallowing function, cognitive ability, and nutritional status had direct effects on ADL. Having fewer teeth leads to wearing dentures, but severe cognitive impairment disrupts denture wearing because of problems with, for example, accessing dental care. Chewing difficulties resulting from having fewer teeth and no dentures can lead to dysphagia. Also cognitive impairment can cause potential problems related to the inability to eat or insufficient access to food, leading to malnutrition $[34,35] . "$

\section{Communication problems}

"Communication is likely to have a significant effect on QoL, considering that it is an ability necessary for instrumental daily life. In particular, stroke patients experience deterioration of social functions due to communication limitations, and when they have difficulty in understanding the meaning of what another party says, or in producing speech, even when they have clear consciousness, it is highly possible that they feel extreme frustration and depression [29]."

\section{Discussion}

Based on the reviewed articles, reducing the problems and improving the conditions of elderly people can be divided into three sections: First, the stage before disability, disease, and their associated problems. Second, the identification and timely diagnosis of disease and problems in elderly people. Finally, the improvement of the conditions of elderly people with disabilities, chronic illnesses, and problems.

Given the issues raised in the papers and the categories of the problems experienced by the elderly (as mentioned in the results section), such problems, apart from the developmental time-specific categories, could be further divided into two other types: physical needs and psychological (mental) needs. As the majority of the papers report, most of the age-related disabilities leave a negative psychological impact on old people, along with the limitations that affect the physical aspects of their lives. In Fig. 3, old people's needs are illustrated based on the distinction between categories of physical needs and psychological needs. As Fig. 3 clarifies, the problems/needs mutually affect each other. Physical problems could intensify psychological ones, while psychological disorder could in turn affect physical wellbeing. Such problems can reinforce one another's impact though the relationships they have in dynamic circles. Finally, all of these needs/problems lead to limitations in performing ADLs.

The needs related to mobility, disabilities, and cognition are significant because such dimensions control many everyday life human activities [31, 32]. Such limitations increase the probability of falling, injury and fracture cases, while preventing the individual from attending open urban spaces or from participating in social activities. This negative experience could deeply affect old people psychologically [36, 42]. Therefore, one of the specifically important concerns in this regard is focusing on the solutions that help the elderly to reduce the impacts of disabilities, especially in the case of impaired motor skills [50-52].

Furthermore, cognitive disorders, along with the needs arising from such disorders, represent another important concern [53-55]. Cognitive disorders, besides generating numerous problems for old people in their ADLs, could

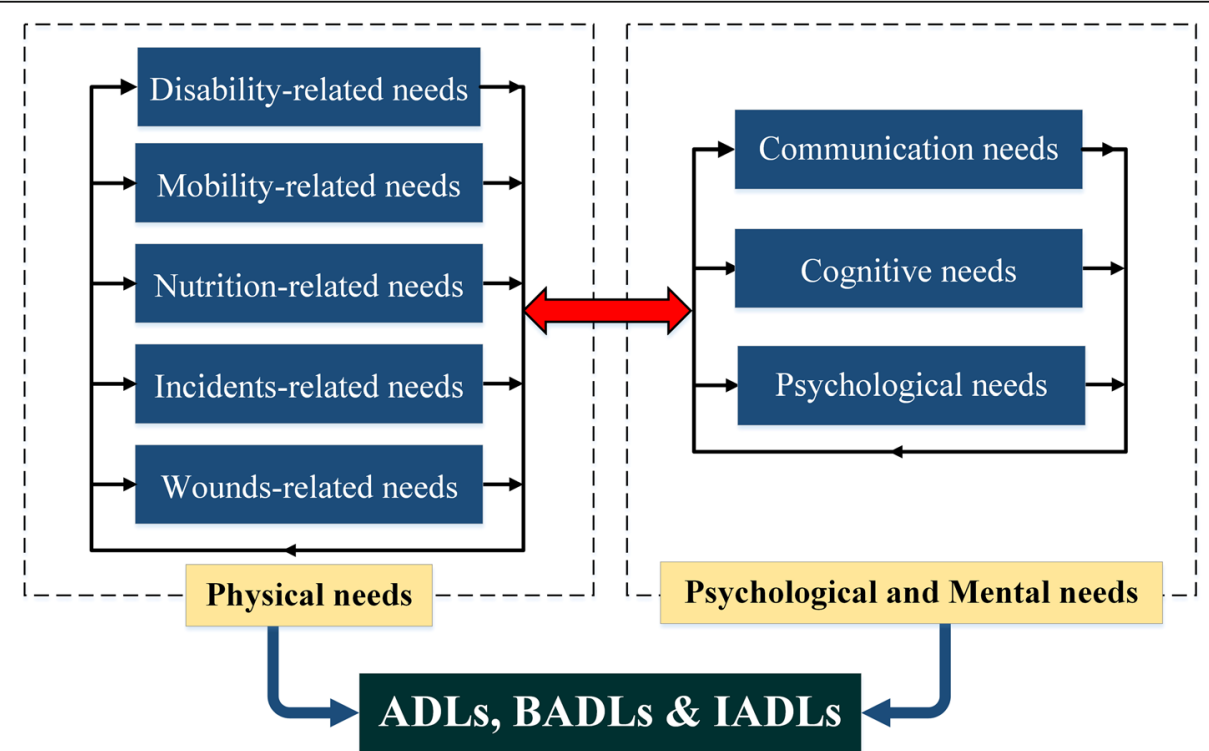

Fig. 3 Seniors' needs based on the distinction made between psychological and physical needs 
even result in malnutrition [30, 34], or injures and fractures.

Many studies have mentioned losing independence, pride and confidence as the most serious psychological issues in the elderly. Not being able to do basic activities could isolate old people and undermine their self-esteem [29]. A wide diversity of studies have shown that the ability to do many activities (e.g. procuring food and cooking) brings about a pleasant sense of independence for the elderly; therefore it would be remarkably important to pay attention to needs that can improve an old individual's independence in addressing his/her personal affairs [34]. Along with these concerns, methods inspiring old people to participate in social activities can prove to be highly important, because depression is one of the consequences of social isolation and limited social interaction [44].

\section{Conclusion}

Chronic diseases can result to ADLs dependency in old age. The major issues that lead to ADLs malfunction in the elderly are disability, psychological disorders, mobility problems, poor cognitive functioning, falling and incidents, wounds and injuries, malnutrition, and communication problems. Within interrelated cycles, old people's problems are interrelated, and each problem can result in other disorders in such people and finally leave a negative impact on their QoL. On this account, the needs of the elderly are divided into two categories, namely the psychological and the physical. Psychological needs include communication, cognitive and psychological needs. Physical needs are associated with disability, mobility, nutrition, incidents, and wounds. Overall, it would be specifically important to pay attention to methods that can enhance old people's cognitive abilities, and to methods that can improve their mobility- and disability-related issues; meanwhile establishing conditions inspiring the elderly to take part in social activities could significantly help to improve their life conditions.

This scoping review supports the view on chronic diseases in old age as a complex issue and to prevent the related problems demands multicomponent interventions which includes early recognition of problems leading to disability and ADL dependence. Education and training for health professionals and the general public, can prevent many problems at different levels. Government support and welfare systems should be designed counting complex needs of elderly people. Additionally, the new, upcoming age will be digital and technology based and therefore technology needs to be oriented to solve this problems, which are grouped by this review in eight categories. Satisfying of elderly people will improve their QoL, which should be the ultimate goal.

\section{Abbreviations}

ADLs: Activities of daily living; IADLs: Instrumental activities of daily living: QoL: Quality of life; WHO: World Health Organization

\section{Acknowledgements}

The authors would like to hereby acknowledge COST Action CA16226 for their networking support. The Indoor Living Space Improvement: Smart Habitat for the Elderly played a role of networking platform for knowledge sharing and interchanging ideas for joint research and publication, what was the base for creating this study. Based on CA16226 project LTC18035 INTER COST was proposed for national funding support of COST ACTION

Framework. COST is a funding agency that helps innovation and research networks. Our Action was instrumental in connecting research programmes throughout the EU region. Their contribution has made it possible for scientists to connect with each other and share their ideas and findings. This allows for more research and better innovation. More information can be found at www.cost.eu. The authors would also like to acknowledge the Excellence 2019 internal research project, Faculty of Informatics and Management, University of Hradec Kralove, Czech Republic.

\section{Authors' contributions}

PM suggested the design of the study and wrote the methodology, supervised whole research; E. searched the databases and prepared the tables; OK, KK, PM interpretation of data and validation of results, visualization; SB, JBH, ST drafted the manuscript; PM, OK, KK, reviewed and revised the paper according to reviewers comments; PM, OK, KK. Project administration and funding acquisition; All authors approved this version of the paper.

\section{Funding}

This work supported in part by the LTC INTER COST, Evaluation of the Potential for Reducing Health and Social Expenses for Elderly People Using the Smart Environment, through the Ministry of Education, Youth and Sports, Czech Republic, under Project LTC18035; and in part by the project of Excellence, University of Hradec Kralove, FIM, Czech Republic (ID: 2205-2019). First author - Petra Maresova is principle investigator of LTC18035 INTER COST project, from which Petra Maresova, Ondrej Krejcar and Kamil Kuca are funded for all expenses including personal costs. Ehsan Javanmardi is funded from project of Excellence ID: 2205-2019 for personal costs. Sabina Barakovic, Jasmina Barakovic Husic and Signe Tomsone are members of COST ACTION 16226 of which also Petra Maresova and Ondrej Krejcar are paticipants, while this article also ACKnowledge this project CA16226.

\section{Availability of data and materials}

The datasets and material used and/or analysed during the current study are available from the corresponding author upon reasonable request.

Ethics approval and consent to participate

Not applicable.

\section{Consent for publication}

Not applicable.

\section{Competing interests}

The authors declare that they have no competing interests.

\section{Author details}

${ }^{1}$ Department of Economics, Faculty of Informatics and Management, University of Hradec Kralove, Rokitanskeho 62, 50003 Hradec Kralove, Czech Republic. ${ }^{2}$ Faculty of Traffic and Communications, University of Sarajevo, Sarajevo, Bosnia and Herzegovina. ${ }^{3}$ Faculty of Electrical Engineering, University of Sarajevo, Sarajevo, Bosnia and Herzegovina. ${ }^{4}$ Faculty of Rehabilitation, Riga Stradinš University, Riga, Latvia. ${ }^{5}$ Center of Basic and Applied Research, Faculty of Informatics and Management, University of Hradec Kralove, Rokitanskeho 62, 50003 Hradec Kralove, Czech Republic. ${ }^{6}$ Malaysia Japan International Institute of Technology (MJIT), Universiti Teknologi Malaysia Kuala Lumpur, Jalan Sultan Yahya Petra, 54100 Kuala Lumpur, Malaysia. 


\section{Received: 7 April 2019 Accepted: 11 October 2019} Published online: 01 November 2019

\section{References}

1. Beard $J R$, et al. The world report on ageing and health: a policy framework for healthy ageing. Lancet. 2016;387(10033):2145-54.

2. Hill AL, Russell MM. The special needs of elderly patients. Seminars Colon Rectal Surg. 2013;24(4):200-8

3. World Health Organization. Global health and aging. Geneva: World Health Organization; 2011.

4. World Health Organization. Towards policy for health and ageing. Geneva: World Health Organization; 2002.

5. Shrivastava SRBL, Shrivastava PS, Ramasamy J. Health-care of elderly: determinants, needs and services. Int J Prev Med. 2013;4(10):1224-5.

6. Jeong $\mathrm{JH}$. The factors affecting on elderly' life satisfaction in the residential environments. Architect Res. 2014;16(4):149-56.

7. Khosravi P, Ghapanchi AH. Investigating the effectiveness of technologies applied to assist seniors: a systematic literature review. Int J Med Inform. 2016;85(1):17-26.

8. R. Reynolds et al., "A systematic review of chronic disease management interventions in primary care," BMC Fam Pract, vol. 19, no. 1, p. 11, 092018.

9. A. Boutayeb and S. Boutayeb, "The burden of non communicable diseases in developing countries," Int J Equity Health, vol. 4, no. 1, p. 20, 2005.

10. "Chronic Diseases in America | CDC," 15-Apr-2019. [Online]. Available: https://www.cdc.gov/chronicdisease/resources/infographic/chronic-diseases. htm. [Accessed: 20-Jul-2019].

11. B. Pache, P. Vollenweider, G. Waeber, and P. Marques-Vidal, "Prevalence of measured and reported multimorbidity in a representative sample of the Swiss population," BMC Public Health, vol. 15, no. 1, p. 65, 2015.

12. Preventing chronic diseases: A vital investment : overview. Geneva and [Ottawa]: World Health Organization and Public Health Agency of Canada, 2005.

13. K. van Dyke, "The Incredible Costs of Chronic Diseases: Why they Occur and Possible Preventions and/or Treatments," J Health Educ Res Development, vol. 4, no. 3, 2016.

14. Sambamoorthi U, Tan X, Deb A. Multiple chronic conditions and healthcare costs among adults. Expert Review Pharmacoeconomics Outcomes Res. 2015:15(5):823-32

15. C. Bähler, C. A. Huber, B. Brüngger, and O. Reich, "Multimorbidity, health care utilization and costs in an elderly community-dwelling population: a claims data based observational study," BMC Health Services Research, vol. 15, no. 1, p. 75,2015

16. "Public health and chronic disease cost savings and return on investment," American Public Health Association, 2016. [Online]. Available: https://www. apha.org/ /media/files/pdf/factsheets/chronicdiseasefact_final.ashx.

17. Sauver JLS, et al. Risk of developing multimorbidity across all ages in an historical cohort study: differences by sex and ethnicity. BMJ Open. 2015; 5(2):e006413.

18. Thorpe KE, Allen L, Joski P. The role of chronic disease, obesity, and improved treatment and detection in accounting for the rise in healthcare spending between 1987 and 2011. Appl Health Econ Health Policy. 2015; 13(4):381-7.

19. Bhattacharya R, Ajmera M, Bhattacharjee S, Sambamoorthi U. Use of antidepressants and statins and short-term risk of new-onset diabetes among high risk adults. Diabetes Res Clin Pract. 2014;105(2):251-60.

20. H. Gilmour and J. Park, "Dependency, chronic conditions and pain in seniors," Health Rep, vol. 16 Suppl, pp. 21-31, 2006.

21. Huang F-H. Explore home care needs and satisfaction for elderly people with chronic disease and their family members. Procedia Manufacturing. 2015;3:173-9.

22. M. G. Lima, M. B. de A. Barros, C. L. G. César, M. Goldbaum, L. Carandina, and R. M. Ciconelli, "Impact of chronic disease on quality of life among the elderly in the state of São Paulo, Brazil: a population-based study," Revista Panamericana de Salud Pública, vol. 25, no, 4, 2009

23. Government Office for Science. Future of an Ageing Population, 2016

24. A. Alla, E. Zdravevski, and V. Trajkovik, "Framework for aiding surveys by natural language processing," 2017

25. E. Glickman, "Activities of Daily Living," MOJ Orthope Rheumatol, vol. 2, no. 2, 2015

26. Hay WW, Levin MJ, Deterding RR, Abzug MJ. Current diagnosis \& treatment: Pediatrics, twenty-second edition. New York: McGraw-Hill Education; 2014.
27. South-Paul JE, Matheny SC, Lewis EL. Current diagnosis \& treatment in family medicine, 3rd ed. New York: McGraw-Hill Medical; 2011.

28. M. del C. Alva, M. Irigoyen Camacho, J. Delgadillo-velazquez, and I. Lazarevich, "The Relationship Between Sarcopenia, Undernutrition, Physical Mobility and Basic Activities of Daily Living in a Group of Elderly Women of Mexico City.," Nutricion hospitalaria : organo oficial de la Sociedad Espanola de Nutricion Parenteral y Enteral, vol. 28, pp. 514-521, Jan. 2014.

29. Byeon $\mathrm{H}$, Koh HW. The relationship between communication activities of daily living and quality of life among the elderly suffering from stroke. J Phys Ther Sci. 2016;28(5):1450-3.

30. Charernboon T, Lerthattasilp T. Characteristic profiles of activities of daily living and relationship with cognitive performance in Thai elderly with different stages from Normal cognitive function, mild cognitive impairment to dementia. Clin Gerontol. 2016;39(4):307-23.

31. S. Chen et al., "Unmet needs of activities of daily living among a community-based sample of disabled elderly people in Eastern China: a cross-sectional study," BMC Geriatrics, vol. 18, no. 1, p. 172, 2018.

32. A. M. Costa Filho, J. V. de M. Mambrini, D. C. Malta, M. F. Lima-Costa, and S. V. Peixoto, "Contribution of chronic diseases to the prevalence of disability in basic and instrumental activities of daily living in elderly Brazilians: the National Health Survey (2013)," Cadernos de Saúde Pública, vol. 34, no. 1, p. 1199, 2018.

33. S. Farías-Antúnez, N. P. Lima, I. O. Bierhals, A. P. Gomes, L. S. Vieira, and E. Tomasi, "Incapacidade funcional para atividades básicas e instrumentais da vida diária: um estudo de base populacional com idosos de Pelotas, Rio Grande do Sul, 2014*", Epidemiologia e Serviços de Saúde, vol. 27, no. 2, 2018.

34. Furuta $M$, et al. Interrelationship of oral health status, swallowing function, nutritional status, and cognitive ability with activities of daily living in Japanese elderly people receiving home care services due to physical disabilities. Community Dent Oral Epidemiol. 2013:41(2):173-81.

35. Genkai S, Kikutani T, Suzuki R, Tamura F, Yamashita Y, Yoshida M. Loss of occlusal support affects the decline in activities of daily living in elderly people receiving home care. J Prosthodontic Research. 2015;59(4):243-8.

36. Ha E, Kim K. Factors that influence activities of daily living in the elderly with probable dementia. J Psychiatr Ment Health Nurs. 2014;21(5):447-54.

37. Hesseberg K, Bentzen $H$, Ranhoff AH, Engedal K, Bergland A. Disability in instrumental activities of daily living in elderly patients with mild cognitive impairment and Alzheimer's disease. Dement Geriatr Cogn Disord. 2013; 36(3-4):146-53.

38. Hou C, et al. Trends of activities of daily living disability situation and association with chronic conditions among elderly aged 80 years and over in China. J Nutr Health Aging. 2018;22(3):439-45.

39. N. Masoudi Alavi, A. Safa, and M. Abedzadeh-Kalahroudi, "Dependency in Activities of Daily Living Following Limb Trauma in Elderly Referred to Shahid Beheshti Hospital, Kashan-Iran in 2013," Archives Trauma Res, vol. 3, no. 3, 2014

40. Okabe T, et al. Age-specific risk factors for incident disability in activities of daily living among middle-aged and elderly community-dwelling Japanese women during an 8-9-year follow up: the Hizen-Oshima study. Geriatr Gerontol Int. 2017;17(7):1096-101.

41. Orive $\mathrm{M}$, et al. Changes in health-related quality of life and activities of daily living after hip fracture because of a fall in elderly patients: a prospective cohort study. Int J Clin Pract. 2015:69(4):491-500.

42. Quail JM, Wolfson C, Lippman A. Unmet need for assistance to perform activities of daily living and psychological distress in community-dwelling elderly women. Canadian J Aging La Revue canadienne du vieillissement. 2011;30(4):591-602

43. da C. silva A, Ferreira RC, Ferreira MAA, de F. Ribeiro MT. Association between the degree of physical impairment from leprosy and dependence in activities of daily living among the elderly in a health unit in the state of Minas Gerais. Rev Soc Bras Med Trop. 2014;47(2):212-7.

44. Takemasa $\mathrm{S}$, et al. Interrelationship among the health-related and subjective quality of life, daily life activities, instrumental activities of daily living of community-dwelling elderly females in orthopedic outpatients. J Phys Ther Sci. 2017;29(5):880-3

45. Liu Y-H, Chang $\mathrm{H}-J$, Huang $\mathrm{C}-\mathrm{C}$. The unmet activities of daily living (ADL) needs of dependent elders and their related factors: an approach from both an individual- and area-level perspective. Int J Gerontol. 2012:6(3):163-8.

46. Putthinoi S, Lersilp S, Chakpitak N. Performance in daily living activities of the elderly while living at home or being home-bound in a Thai suburban community. Procedia Environ Sci. 2016;36:74-7. 
47. Ohri P, Kumar Gupta S, Upadhyai N. A study of daily living dependency status among elderly in an urban slum area of Dehradun. Indian J Community Health. Dec. 2014;26:420-5.

48. L. V. de Oliveira Brito, G. A. Maranhao Neto, H. Moraes, R. F. e. S. Emerick, and A. C. Deslandes, "Relationship between level of independence in activities of daily living and estimated cardiovascular capacity in elderly women," Arch Gerontol Geriatr, vol. 59, no. 2, pp. 367-371, 2014.

49. A. Safa, N. Masoudi Alavi, and M. Abedzadeh-Kalahroudi, "Predictive Factors of Dependency in Activities of Daily Living Following Limb Trauma in the Elderly," Trauma Monthly, vol. 21, no. 5, 2016.

50. Kikhia B, Gomez M, Jiménez L, Hallberg J, Karvonen N, Synnes K. Analyzing body movements within the Laban effort framework using a single accelerometer. Sensors. 2014;14(3):5725-41.

51. S. B. Khojasteh, J. R. Villar, C. Chira, V. M. González, and E. de La Cal, "Improving Fall Detection Using an On-Wrist Wearable Accelerometer," Sensors (Basel, Switzerland), vol. 18, no. 5, 2018.

52. K. de Miguel, A. Brunete, M. Hernando, and E. Gambao, "Home CameraBased Fall Detection System for the Elderly," Sensors (Basel, Switzerland), vol. 17, no. 12, 2017.

53. S. Zhao, W. Li, and J. Cao, "A User-Adaptive Algorithm for Activity Recognition Based on K-Means Clustering, Local Outlier Factor, and Multivariate Gaussian Distribution," Sensors (Basel, Switzerland), vol. 18, no. 6,2018

54. A. S. A. Sukor, A. Zakaria, and N. A. Rahim, "Activity recognition using accelerometer sensor and machine learning classifiers," in 2018 IEEE 14th International Colloquium on Signal Processing \& Its Applications (CSPA), pp. 233-238.

55. Mehrang S, Pietilä J, Korhonen I. An activity recognition framework deploying the random Forest classifier and a single optical heart rate monitoring and Triaxial accelerometer wrist-band. Sensors. 2018;18:613.

\section{Publisher's Note}

Springer Nature remains neutral with regard to jurisdictional claims in published maps and institutional affiliations.

Ready to submit your research? Choose BMC and benefit from:

- fast, convenient online submission

- thorough peer review by experienced researchers in your field

- rapid publication on acceptance

- support for research data, including large and complex data types

- gold Open Access which fosters wider collaboration and increased citations

- maximum visibility for your research: over $100 \mathrm{M}$ website views per year

At $\mathrm{BMC}$, research is always in progress.

Learn more biomedcentral.com/submissions 